\title{
METABOLOMICS ANALYSIS ON DIFFERENT PARTS OF ACANTHOPANAX SENTICOSUS BASED ON UPLC-Q-TOF-MS
}

\author{
LIJIE ZUO ${ }^{1}$, XIAOJIN GE ${ }^{2}$, MAOGAO CHENG ${ }^{1}$, QINGMEI QIAO ${ }^{1}$, LIHONG LI ${ }^{1}$, HUIFANG LV $^{1}$, \\ ZHIKUN XU ${ }^{1}$, and SHUYA XU' ${ }^{1 *}$
}

\author{
${ }^{1}$ College of Animal Medicine, Henan University of Animal Husbandry and Economy, \\ Zhengzhou 450046, P. R. China \\ ${ }^{2}$ Economic Crop Research Institute, Henan Academy of Agricultural Sciences, \\ Henan Provincial Engineering Technology Research Center of Economic Crop Seedling, \\ Zhengzhou 450008, P. R. China
}

\begin{abstract}
Acanthopanax senticosus roots, rhizomes, or stems are the main site of ciwujia. Due to the limited resources of the roots, the leaves and pulp are sometimes used as health products or medication sites. In order to utilize the leaves and pulp, it is important to conduct the chemical comparison of the roots, leaves, and pulp of A. senticosus. In this study, Multivariate statistical analysis and UPLC-Q-TOF-MS/ MS was used to compare the chemical composition of the roots, leaves, pulp of A. senticosus, a total of 47 compounds were identified. The results suggested that the content of lignans, such as Eleutheroside $\mathrm{D}$, Eleutheroside E, were so much higher in the roots than those in the leaves and pulp. The content of Eleutheroside B is similar between the roots and the pulp of $A$. senticosus and is so much higher in the roots, pulp than that in the leaves. This result laid a certain foundation for the pulp of $A$. senticosus to replace the roots as a medication site in some pharmacological effects. The leaves cannot replace the roots as a medication site due to the low content of Eleutheroside compounds. This study laid the foundation for the rational utilization of $A$. senticosus resources.
\end{abstract}

Keywords: Acanthopanax senticosus, UPLC-Q-TOF-MS/MS, multivariate statistical analysis, metabolomic

Acanthopanax senticosus (Rupr. et Maxim) Harms, is commonly known as Siberian ginseng or ciwujia in Chinese. A. senticosus is widely distributed in the Northeastern part of China $(1,2)$. It is a traditional Chinese medicine widely prescribed to nourish qi, fortify the spleen, tonify the kidney and tranquilize the mind (3). Ciwujia injection is a traditional Chinese medicine injection made by extracting A. senticosus (4). Eleutheroside B (also named Syringin), Eleutheroside E, and Isazididine are the main active ingredients of ciwujia injection. Ciwujia injection is used alone or in combination for cardiovascular diseases and other neurological diseases, such as cerebral infarction, insomnia, Alzheimer's disease $(5,6)$. Since its definite curative effect and its excessive mining, the wild resources of $A$. senticosus are seriously inadequate, comprehensive development and utilization of new medicinal parts is imminent.

A. senticosus injections and tablets which used roots or stem are widely used in clinical medicine, while $A$. senticosus leaves and pulp may be similar to roots in some pharmacological activities. Probably due to the ingredients contained in the pulp are similar to those in the roots, such as Eleutheroside A, Eleutheroside B, Eleutheroside E, and Isazididine (7). Kuzniewski et al proved that protocatechuic acid is the most abundant component in the leaves of $A$. senticosus through LCESI-MS/MS and the leaves have very weak AchE activity (8). From the perspective of medicinal resources, leaves and pulp have obvious advantages over roots. In addition, a previous study developed a liquid chromatography-mass spectrometry method to analyze the constituents in roots and leaves ( 9 , 10). However, it is still a question whether $A$. senticosus leaves or pulp can replace $A$. senticosus roots as a medication site in certain pharmacological effects. Therefore, systematically comparing the components of leaves, pulp, and roots of $A$. senticosus is of great significance for promoting the effective use of $A$. senticosus resources.

* Corresponding author: e-mail: xsy1314663@163.com 
Metabolomics (or metabolic profiling) is an important part of systems biology that focuses on the identification of some small molecule $(<1500 \mathrm{Da})$ compounds in the metabolome(11-16). Metabolomics has shown potential in the bioactivity evaluation and action mechanism of Traditional Chinese Medicine (TCM) as well as pharmaceutical research and development(17). Various studies have shown that metabolomics often uses the UHPLC-MS platform to analyze a series of metabolomics data efficiently to monitor the differences in various metabolites in body fluid (18-20).

This research intends to discuss the similarities and differences of the roots, leaves, pulp of A. senticosus using UPLC-HDMS, combined with MassLynx 4.0, Progenesis QI, PCA (principal components analysis), UNIFI 8.1. The results of this study will lay the foundation for the utilization of $A$. senticosus resources.

\section{MATERIALS AND METHODS}

\section{Plant materials}

The roots, leaves, and pulp samples of $A$. senticosus were bought from the traditional Chinese medicinal material market in Bozhou (China), and the sample of Acanthopanax pulp is dried directly after picking. All samples are dried processed in the place of production. The information of all samples is as follows: The first batch, the second batch, and the third batch of samples originated from Jilin (China), and the numbers are 20170901, 20170902, 20170903, and the fourth, fifth, and sixth batches are from Heilongjiang (China), and the numbers are 20170904, 20170905, and 20170906. All samples were identified as $A$. senticosus by professor Qingmei Qiao from the College of Animal Medicine, Henan University of Animal Husbandry and Economy. All samples after drying in the place of production were dried at $40^{\circ} \mathrm{C}$ for $3 \mathrm{~h}$ in the laboratory and stored at room temperature before measurements.

\section{Reagents}

Acetonitrile and formic acid (LC/MS grade) were purchased from Thermo Fisher Co. (Waltham, MA, USA). Ultra-pure water was prepared using a Millipore Milli-Q purification system (Millipore Corp., Bedford, Mass., USA). All other reagents were of analytical grade.

\section{Preparation of sample solutions}

All dried roots, leaves, and pulp samples were broken into powder and filtered through a No. 65 sieve. In brief, $500 \mathrm{mg}$ of per sample was weighed into a $10 \mathrm{~mL}$ tube, and $5 \mathrm{~mL}$ of methanol/water $(1: 1)$ was added. The sample powder was extracted for $20 \mathrm{~min}$ in an ultrasonic bath at $25^{\circ} \mathrm{C}$. The supernatant solution was filtered through $0.22 \mu \mathrm{m}$ PTFE membrane filter before injected into the UPLC system.

\section{UPLC-HDMS}

Chromatographic experiments were performed as described previously $(21,22)$. All sample extracts were analyzed using a Waters UHPLC-QTOF-ESIMS system, including a Waters, Milford UHPLC system, and Xevo G2 Q-TOF MS equipped with an electrospray ionization (ESI) source (Waters, Milford, MA, USA). The samples were injected onto an ACQUITY BEH $\mathrm{C}_{18}$ column $(2.1 \times 100 \mathrm{~mm}$, particle size $1.7 \mu \mathrm{m}$ ) by gradient elution. During analysis, the column temperature was maintained at $40^{\circ} \mathrm{C}$ and the flow rate was set $0.3 \mathrm{~mL} / \mathrm{min}$ throughout the gradient. $0.1 \%(\mathrm{v} / \mathrm{v})$ formic acid-water and acetonitrile were used as solution A and solution B. The following gradient profile was employed: $0-2 \mathrm{~min}, 6 \% \mathrm{~B}$; 2-15 $\min , 6 \%-100 \% \mathrm{~B}$; $15-15.1 \mathrm{~min}, 100 \%-6 \% \mathrm{~B}$; 15.1-17 min, $6 \% \mathrm{~B}$.

The injection volume was $5 \mu \mathrm{L}$. A dual ESI source was operated in positive ion mode $\left(\mathrm{ESI}^{+}\right)$. The mass range was set to acquire over m/z 50-2000 Da. The detailed MS conditions were as follows: source temperature of $130^{\circ} \mathrm{C}$, desolvation temperature of $350^{\circ} \mathrm{C}$, cone gas flow of $50 \mathrm{~L} / \mathrm{h}$, desolvation gas flow of $700 \mathrm{~L} / \mathrm{h}$, a capillary voltage of $2.5 \mathrm{kV}$, sample cone voltage of $21 \mathrm{~V}$, extraction cone of $4 \mathrm{eV}$, collision energy of $15 \mathrm{eV}$. The leucine-enkephalin was continuously injected as a reference to ensure accuracy, which was detected during the run at a concentration of $500 \mathrm{pg} / \mu \mathrm{L}$.

\section{Data processing and multivariate statistical analysis}

The mass chromatographic data acquisition and analyses of data were controlled by Waters MassLynx v4.0 software (Waters Corp.) and UNIFI v1.8.1 software (Waters Corp.). All chromatographic data were preprocessed and normalized. The MarkerLynx software and UNIFI software were used to calculate the $\mathrm{ESI}^{+}$raw data of all samples. A two-dimensional matrix consisting of data pairs of retention time (RT) and mass-to-charge ratio $(\mathrm{m} / \mathrm{z})$ was generated, and the mass values and intensities of peaks were exported to Excel for further chemometric analysis. Then, the data from Markerlynx were exported to SIMCA 13.0.3 software (Umetrics, Umeå, Sweden) for principal component analysis (PCA) and orthogonal partial least squares discriminant analysis (OPLS-DA), 

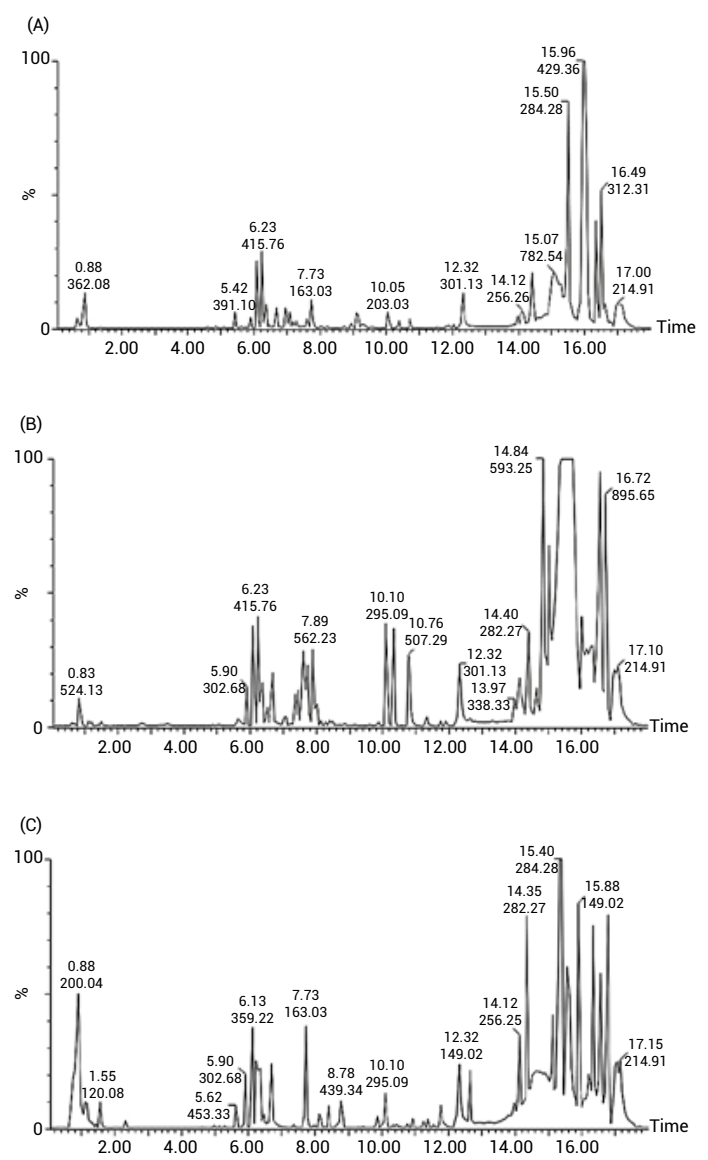

Figure 1. The BPI chromatograms from UPLC-HDMS of $A$. senticosus. The extracts of the roots (A), leaves (B), and pulp (C) were analyzed in positive ion mode.

which was used to identify different components among the three groups.

\section{RESULTS AND DISCUSSION}

\section{UPLC-HDMS analysis}

MS data were obtained in positive ion mode. Most constituents exhibited their quasi-molecular ions $[\mathrm{M}+\mathrm{H}]^{+}$ ions in the positive ion mode. The based peak intensity (BPI) chromatograms of the roots, leaves, pulp were presented in Figure 1. Visual inspection of the spectra from the different parts of $A$. senticosus revealed obvious differences with each other. Accurate molecular data of each potential marker were determined up to four decimal places using UPLCHDMS. Identification of compounds was achieved by comparison to mass spectral data in the available literature. The data were presented in Table 1.

\section{Multivariate statistical analysis}

Typically, PCA (Principal Components Analysis) can reduce the dimension of metabolites matrices based on their linear combinations of mutual features in the dataset. PCA is generally used for plotting the grouping and visualizing outliers based on natural interrelationships between samples (23). The peak list containing retention time, $\mathrm{m} / \mathrm{z}$, and ion intensity of each sample was imported into the SIMCA-P Software for multivariate statistical analysis, which was processed by PCA for discriminating all samples from different parts of A. senticosus. All metabolites were displayed as scores and loadings in a coordinate system of principal components resulting from data dimensionality reduction. The PCA scores plots of data were shown in Figure 2. UV scaling was used to perform PCA. $\mathrm{R}^{2}=0.749$ and $\mathrm{Q}^{2}=0.559$ suggested the model performed a relatively excellent prediction. Based on Figure 2, samples of roots are positioned on the right side and the top side (positive $t$ [1] values and positive $t$ [2] values) of the PCA score plot whereas the samples of leaves are located on the right side and the below side (positive t [1] values and negative $t$ [2] values), the samples of pulp are located on the left side (negative t [1] values). These three classes can be separated clearly from each other.

In order to further explore the difference between different parts of $A$. senticosus, OPLS-DA (orthogonal partial least squares discriminant analysis) approach was applied to enhance the separation among the groups in PCA. Par scaling was used to perform OPLS-DA. As shown in Figure3A, applying the OPLS-DA study, samples were clearly separated in the scores plot. In the corresponding S-plot (Figure 3B), each point represented an ion $\mathrm{RT}-\mathrm{m} / \mathrm{z}$ pair. When the variables with importance

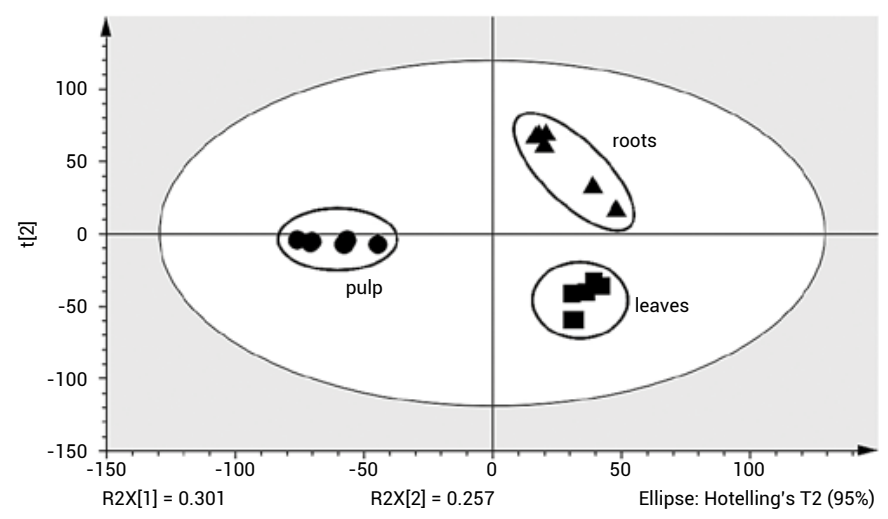

Figure 2. PCA score plot of the roots, leaves, and pulp, based on UPLC-HDMS 


\begin{tabular}{|c|c|c|c|c|c|c|c|c|c|c|c|c|c|c|c|c|c|c|c|c|c|c|}
\hline 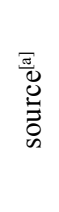 & 을 & 을 & 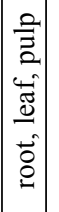 & 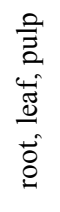 & $\begin{array}{l}\stackrel{2}{\Xi} \\
\stackrel{0}{0} \\
\stackrel{0}{0}\end{array}$ & 웧 & 웧의 & 읗 & 空 & $\left|\begin{array}{|c}0 \\
\bar{z} \\
\vdots \\
0 \\
0 \\
0\end{array}\right|$ & 苂 & $\stackrel{\circ}{\circ}$ & 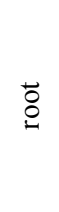 & 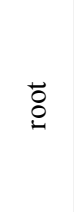 & 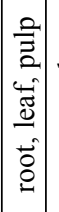 & & $\begin{array}{l}0 \\
0 \\
0\end{array}$ & 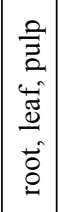 & 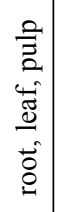 & 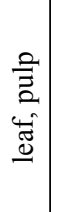 & : & 을 \\
\hline 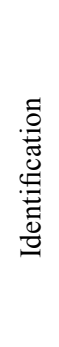 & 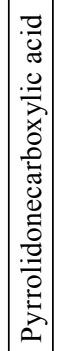 & 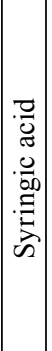 & $\left|\begin{array}{l}0 \\
0 \\
0 \\
0 \\
0 \\
1 \\
\hat{ \pm} \\
1 \\
0\end{array}\right|$ & 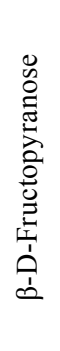 & \begin{tabular}{|l}
$\overline{\overline{0}}$ \\
$\overline{\frac{5}{5}}$
\end{tabular} & 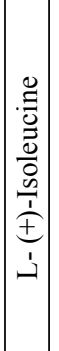 & 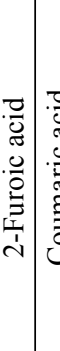 & 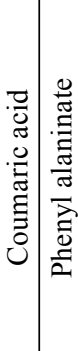 & 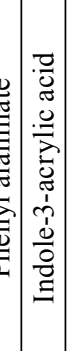 & 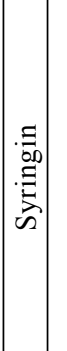 & 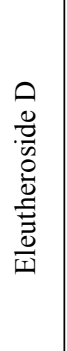 & 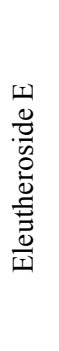 & 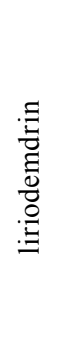 & 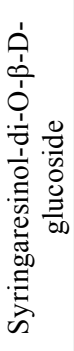 & 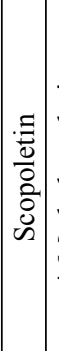 & 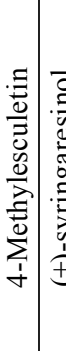 & 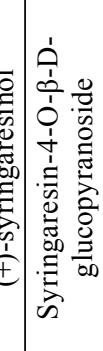 & 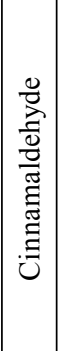 & 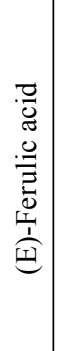 & 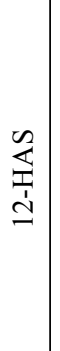 & 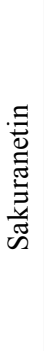 & 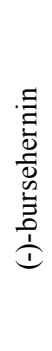 \\
\hline
\end{tabular}

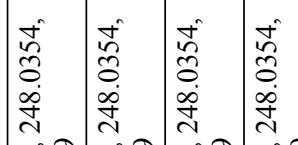

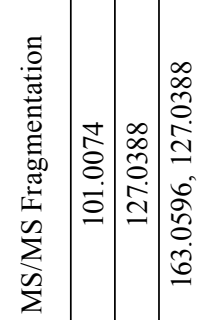

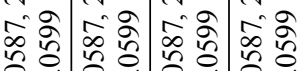

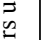

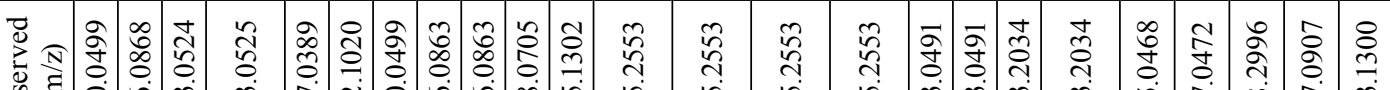

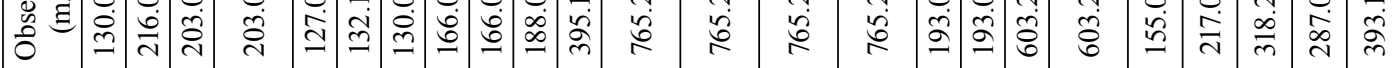

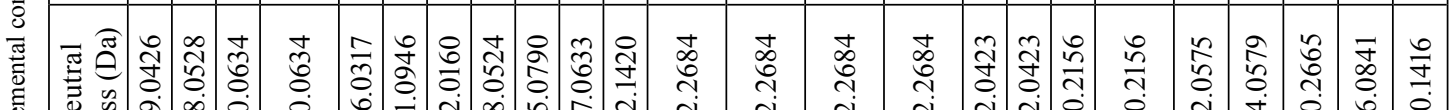

\begin{tabular}{|c|c|c|c|c|c|c|c|c|c|c|c|c|c|c|c|c|c|c|c|c|c|c|}
\hline 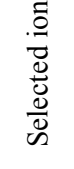 & $\begin{array}{l}\Xi \\
+ \\
\Sigma\end{array}$ & \begin{tabular}{l|l}
$\bar{z}$ & \multicolumn{2}{c}{} \\
+ & + \\
$\sum$ & + \\
$\Sigma$
\end{tabular} & 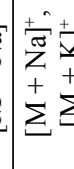 & $\begin{array}{l}\text { It } \\
+ \\
\Sigma\end{array}$ & $\left|\begin{array}{l}\Xi \\
\pm \\
\Sigma\end{array}\right|$ & \begin{tabular}{lll} 
& \multicolumn{1}{c}{} \\
$z$ & $z$ \\
+ & + \\
\pm & +
\end{tabular} & 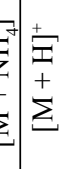 & $\mid \begin{array}{l}\Xi \\
+ \\
\Sigma\end{array}$ & $\mid \begin{array}{l}7 \\
\tilde{z} \\
+ \\
\Sigma \\
\Sigma\end{array}$ & 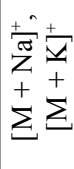 & 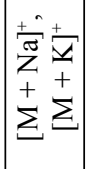 & $\begin{array}{l}Z_{4}^{\circ} \\
+ \\
\end{array}$ & $\begin{array}{l}\frac{\pi}{Z} \\
+ \\
+\end{array}$ & $\left|\begin{array}{l}+ \\
ت \\
+ \\
\Sigma\end{array}\right|$ & $\begin{array}{l}7 \\
ت \\
+ \\
+\end{array}$ & $\begin{array}{l}z \\
z \\
+ \\
\Sigma\end{array}$ & \begin{tabular}{l|}
$\bar{z}$ \\
\\
+ \\
$\Sigma$
\end{tabular} & $\begin{array}{l}\vec{T} \\
\tilde{z} \\
+ \\
\Sigma\end{array}$ & $\begin{array}{l}\vec{z} \\
+ \\
\pm \\
\Sigma\end{array}$ & $\begin{array}{l}\bar{B}^{+} \\
\pm \\
\Sigma\end{array}$ & $\begin{array}{l}t \\
T \\
+ \\
\Sigma\end{array}$ & $\begin{array}{l}\vec{T} \\
\pm \\
\pm \\
\Sigma\end{array}$ \\
\hline 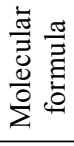 & $\begin{array}{c}0 \\
Z \\
= \\
0 \\
0 \\
0\end{array}$ & $\begin{array}{ll}I^{9} \\
0^{\circ}\end{array}$ & $\begin{array}{l}0^{\circ} \\
I^{2}\end{array}$ & 定 & $\mid \begin{array}{l}0 \\
z \\
z_{-1} \\
0 \\
0\end{array}$ & $\begin{array}{lll}0 & 0 \\
0^{-1} \\
0\end{array}$ & 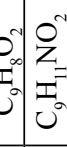 & $\mid \begin{array}{l}0^{0} \\
z^{\circ} \\
u^{\circ}\end{array}$ & $\begin{array}{l}0_{0}^{\circ} \\
\underbrace{n} \\
0 \\
0\end{array}$ & $\begin{array}{l}O_{\infty}^{\infty} \\
=_{-\infty}^{+} \\
U^{\infty}\end{array}$ & $\begin{array}{l}0_{0}^{\infty} \\
S_{f}^{+} \\
U^{\infty} \\
U^{+}\end{array}$ & $\begin{array}{l}0^{\infty} \\
\Xi_{\infty}^{+} \\
U^{+}\end{array}$ & $\begin{array}{l}O^{\infty} \\
I_{5}^{+} \\
U^{+}\end{array}$ & & $\begin{array}{ll}0^{+} \\
\underbrace{\infty} \\
0^{0}\end{array}$ & $\begin{array}{l}0^{n} \\
I^{0} \\
0^{\infty}\end{array}$ & $\begin{array}{l}O_{\infty}^{m} \\
=_{\infty}^{m} \\
U^{\infty}\end{array}$ & $\begin{array}{l}O_{\infty}^{\infty} \\
\underset{\Xi^{\infty}}{0^{\prime}}\end{array}$ & $\begin{array}{l}O_{0}^{+} \\
I_{0}^{-} \\
0 \\
0\end{array}$ & $\begin{array}{l}O_{0}^{\infty} \\
=_{\infty}^{\infty} \\
U^{\infty}\end{array}$ & $\begin{array}{l}O_{ \pm}^{n} \\
=_{6}^{ \pm} \\
0^{\prime}\end{array}$ & $\begin{array}{l}O_{0}^{0} \\
\Xi^{0} \\
U^{\sqrt{2}}\end{array}$ \\
\hline 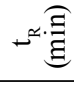 & \begin{tabular}{|l|l} 
\\
$\infty$ \\
0 \\
0
\end{tabular} & 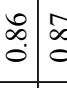 & $\begin{array}{c}\infty \\
\infty \\
0\end{array}$ & 0 & $-i$ & $\vec{m}$ & 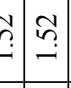 & i & $\begin{array}{l}\stackrel{\dot{v}}{\sim} \\
\stackrel{+}{+} \\
\end{array}$ & $\dot{n}$ & & if & & \begin{tabular}{|c|}
$\hat{\infty}$ \\
$\dot{n}$ \\
\end{tabular} & 4 & & $\frac{7}{6}$ & 6 & $\stackrel{n}{\stackrel{n}{r}}$ & $\stackrel{\circ}{\circ}$ & $\stackrel{\circ}{\circ}$ & $\stackrel{\infty}{\stackrel{\infty}{a}}$ \\
\hline & -1 & $\sim$ & & & 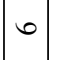 & 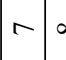 & 1 & 1 & 1 & & & & & & & & & $\approx$ & $\bar{\lambda}$ & & $\tilde{\lambda}$ & \\
\hline
\end{tabular}




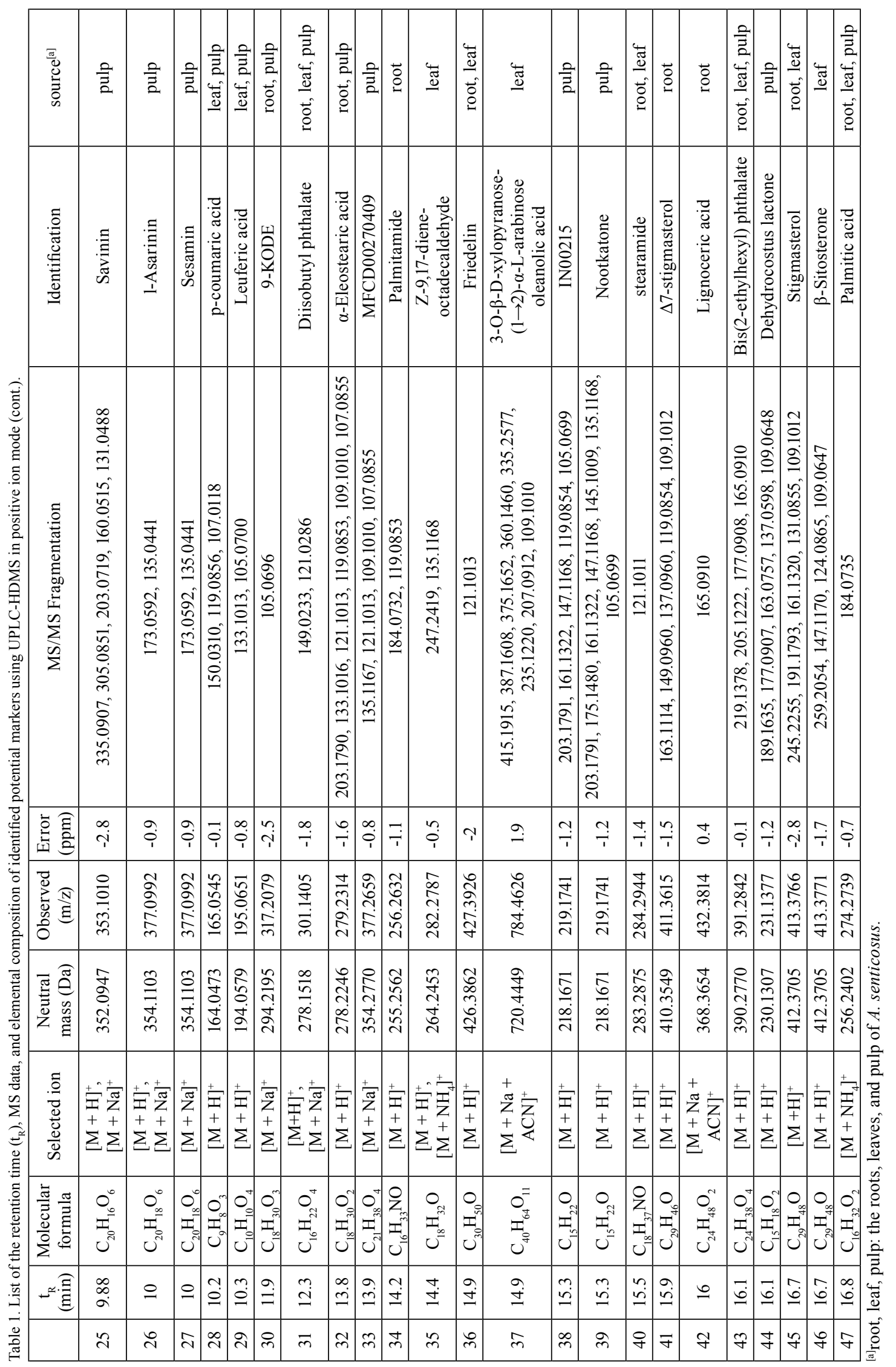


(A)

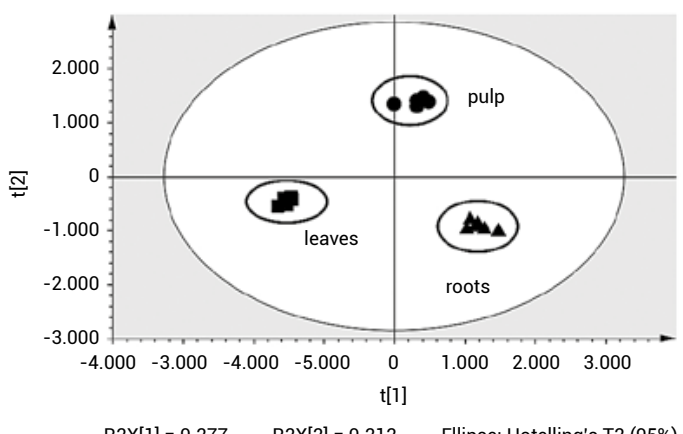

(B)

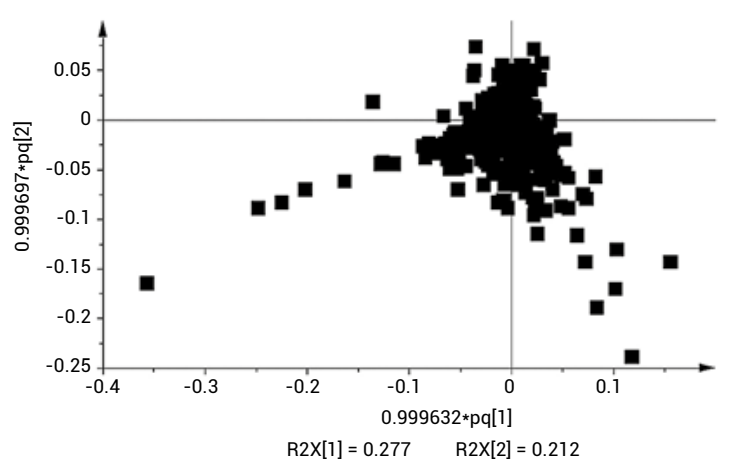

Figure 3. OPLS-DA score plot (A) and corresponding loading scatter plot (B) of the roots, leaves, and pulp, based on UPLC-HDMS.

in projection $(\mathrm{VIP})>1$, the ion $\mathrm{RT}-\mathrm{m} / \mathrm{z}$ pairs were selected as potential chemical markers for the discrimination of the roots, leaves, and pulp.

\section{Comparison of eleven chemical markers}

According to Figure 3B, there were 275 chemical markers of VIP $>1$ which were highlighted in the loading scatter plot of OPLS-DA. After using UNIFI 8.1 to identify the markers, eleven compounds were identified. The detailed information of the markers of VIP $>1$ was summarized in Table 2. In order to provide a further comparison of the differences among roots, leaves, and pulp of $A$. senticosus at different maturation. The difference with $\mathrm{p}<0.001$ was considered significant. In order to further study the difference among roots, leaves, and pulp, the intensity of eleven chemical markers was analyzed by the one-way ANOVA test.

As shown in Figure 4, the marker levels varied considerably among roots, leaves, and pulp. The levels of Eleutheroside D, Eleutheroside E, liriodendrin in the roots showed particularly higher as compared to other parts of the leaves and pulp. The compounds can be used as the specific markers for the differentiation of roots from leaves and pulp. The levels of Indole-3-acrylic acid and 2-furoic acid were found remarkably higher in pulp than in other groups. The level of p-coumaric acid was higher in leaves and

Table 2. Identified maker ions of different parts of $A$. senticosus.

\begin{tabular}{|c|c|c|c|c|c|c|c|}
\hline & $\begin{array}{c}t_{R} \\
(\min )\end{array}$ & Identification & $\begin{array}{l}\text { Molecular } \\
\text { formula }\end{array}$ & Selected ion & MS/MS Fragmentation & Source ${ }^{[a]}$ & VIP \\
\hline 1 & 5.43 & Eleutheroside D & $\mathrm{C}_{34} \mathrm{H}_{46} \mathrm{O}_{18}$ & $\begin{array}{c}{[\mathrm{M}+\mathrm{Na}]^{+}} \\
{[\mathrm{M}+\mathrm{K}]^{+}}\end{array}$ & $\begin{array}{l}\text { 619.1687, 591.2041, 457.1165, 275.0587, } \\
248.0354,205.0860,167.0703,137.0599\end{array}$ & Root & 2.97 \\
\hline 2 & 5.43 & Eleutheroside E & $\mathrm{C}_{34} \mathrm{H}_{46} \mathrm{O}_{18}$ & $\begin{array}{c}{[\mathrm{M}+\mathrm{Na}]^{+}} \\
{[\mathrm{M}+\mathrm{K}]^{+}}\end{array}$ & $\begin{array}{c}619.1687,591.2041,457.1165,275.0587, \\
248.0354,205.0860,167.0703,137.0599\end{array}$ & Root & 2.97 \\
\hline 3 & 5.43 & $\begin{array}{c}\text { Syringaresinol- } \\
\text { di-O- } \beta-\mathrm{D}- \\
\text { glucoside }\end{array}$ & $\mathrm{C}_{34} \mathrm{H}_{46} \mathrm{O}_{18}$ & {$[\mathrm{M}+\mathrm{Na}]^{+}$} & $\begin{array}{c}\text { 619.1687, 591.2041, 457.1165, 275.0587, } \\
248.0354,205.0860,167.0703,137.0599\end{array}$ & Root & 2.97 \\
\hline 4 & 5.43 & Liriodemdrin & $\mathrm{C}_{34} \mathrm{H}_{46} \mathrm{O}_{18}$ & {$[\mathrm{M}+\mathrm{Na}]^{+}$} & $\begin{array}{l}\text { 619.1687, 591.2041, 457.1165, 275.0587, } \\
248.0354,205.0860,167.0703,137.0599\end{array}$ & Root & 2.97 \\
\hline 5 & 0.88 & Maltol & $\mathrm{C}_{6} \mathrm{H}_{6} \mathrm{O}_{3}$ & {$[\mathrm{M}+\mathrm{H}]^{+}$} & 101.0074 & Root, pulp & 1.02 \\
\hline 6 & 4.54 & Syringin & $\mathrm{C}_{17} \mathrm{H}_{24} \mathrm{O}_{9}$ & {$[\mathrm{M}+\mathrm{Na}]^{+}$} & 201.0070 & Root, pulp & 1.25 \\
\hline 7 & 15.33 & IN00215 & $\mathrm{C}_{15} \mathrm{H}_{22} \mathrm{O}$ & {$[\mathrm{M}+\mathrm{H}]^{+}$} & $\begin{array}{c}203.1791,161.1322,147.1168,119.0854 \\
105.0699\end{array}$ & Root, pulp & 1.23 \\
\hline 8 & 15.33 & Nootkatone & $\mathrm{C}_{15} \mathrm{H}_{22} \mathrm{O}$ & {$[\mathrm{M}+\mathrm{H}]^{+}$} & $\begin{array}{c}203.1791,161.1322,147.1168,119.0854 \\
105.0699\end{array}$ & Root, pulp & 1.23 \\
\hline 9 & 10.15 & p-coumaric acid & $\mathrm{C}_{9} \mathrm{H}_{8} \mathrm{O}_{3}$ & {$[\mathrm{M}+\mathrm{H}]^{+}$} & $150.0310,119.0856,107.0118$ & Leaf, pulp & 2.74 \\
\hline 10 & 2.24 & $\begin{array}{l}\text { Indole-3-acrylic } \\
\text { acid }\end{array}$ & $\mathrm{C}_{11} \mathrm{H}_{9} \mathrm{NO}_{2}$ & {$[\mathrm{M}+\mathrm{H}]^{+}$} & 146.0601 & Pulp & 1.13 \\
\hline 11 & 1.31 & 2-Furoic acid & $\mathrm{C}_{5} \mathrm{H}_{4} \mathrm{O}_{3}$ & {$\left[\mathrm{M}+\mathrm{NH}_{4}\right]^{+}$} & 121.9910 & Pulp & 1.22 \\
\hline
\end{tabular}

${ }^{[a]}$ root, leaf, pulp: the roots, leaves, and pulp of A. senticosus. 
Eleutheroside D

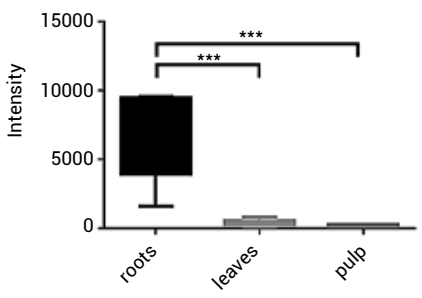

liriodemdrin

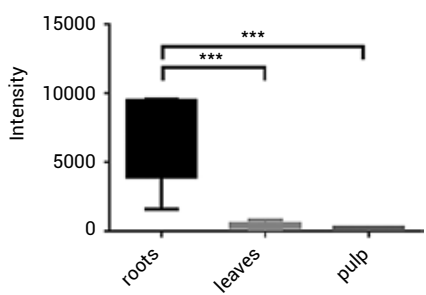

IN00215

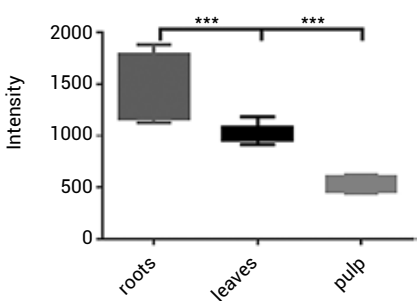

Indole-3-acrylic acid

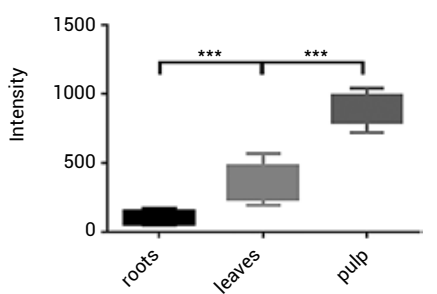

Eleutheroside $\mathrm{E}$
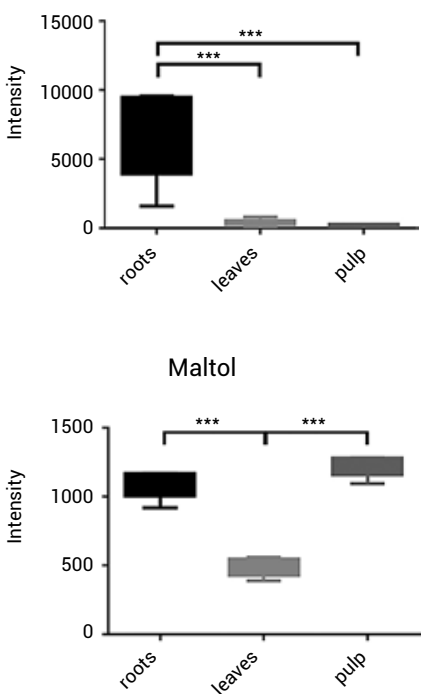

Nootkatone

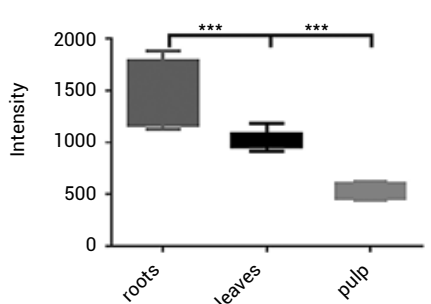

2-Furoic acid

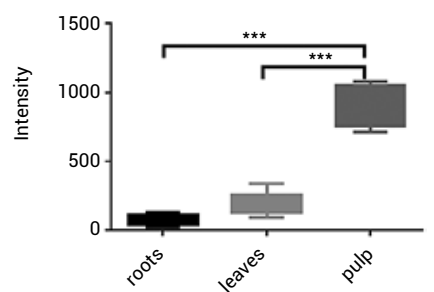

siringaresinol-di-O- $\beta$-D-glucoside
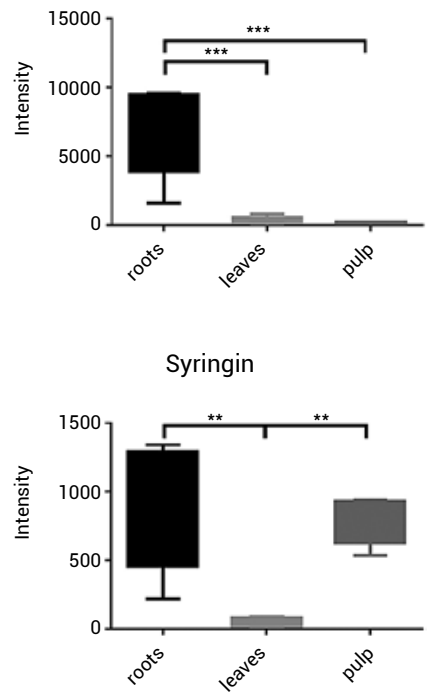

p-coumaric acid

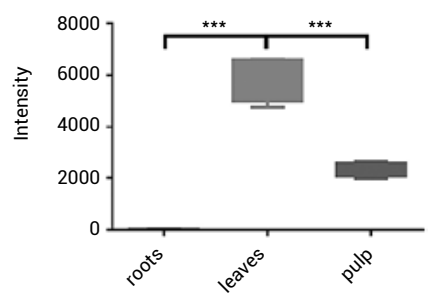

Figure 4. Relative intensities of selected markers in roots, leaves and pulp $(n=6)$. Data represent the mean $\pm \mathrm{SD}$.

$* *$ indicates $\mathrm{p}<0.01$;

$* * *$ indicates $\mathrm{p}<0.001$. pulp than that in roots. The intensity of syringin, the main active component of $A$. senticosus, was found higher in roots, pulp than that in leaves, it may lay a certain foundation for exerting the medicinal value of pulp.

PCA and OPLS-DA score plots from UPLC-MS data showed a clear separation between the roots, leaves, and pulp of $A$. senticosus. A total of $47 \mathrm{com}-$ pounds were identified in roots, leaves, pulp through a UNIFI 8.1 database. The roots contain main active phenylpropanoids, such as Eleutheroside B (syringin), Eleutheroside D, Eleutheroside E, while the leaves are basically free of phenylpropanoids. The pulp contains some phenylpropanoid, such as Eleutheroside B. The pulp also contains many acidic compounds, such as isoleucine, phenylalanine, 2-Furoic acid, coumaric acid, and so on.

Eleven compounds were identified as markers in this study. Those can be used as the specific markers for the differentiation of roots from leaves and pulp. Eleutheroside D and E are the different compounds of $A$. senticosus roots compared with leaves and pulp. The content of Eleutheroside D and E in the roots produced in the Northeast region is much higher than that in the leaves and pulp. The content of Eleutheroside E in the Eleutherococcus senticosus fruits produced in Bydgoszcz (Poland) is very little and almost nothing (24). The content of Eleutheroside B, also named syringin, is similar between the roots and the pulp, and the content of 
Eleutheroside B was found so much higher in the roots, pulp than that in the leaves of $A$. senticosus. But there is no Eleutheroside B in the fruits of E. senticosus in Bydgoszcz (Poland). It is suspected that the content of Eleutheroside B in the A. senticosus fruit is inconsistent due to the different origin. As stated in the introduction, the main active components of ciwujia injection, which is made by extracting the roots of $A$. senticosus, are Eleutheroside B, Eleutheroside E, Isazididine. Eleutheroside B and Eleutheroside $\mathrm{E}$ are the main effective ingredient for the treatment of cardiovascular diseases and neurological diseases, which is consistent with the various effects of clinical application of $A$. senticosus, such as angina, anti-fatigue, anti-cancer, etc. This may be one of the reasons why the roots can be the medication site of $A$. senticosus.

The content of Eleutheroside B is similar between the roots and the pulp. Thus we speculate that the pulp of $A$. senticosus may also have a certain pharmacological effect. The pulp of $A$. senticosus may be used as a substitute for the roots in some pharmacological effects, but it still needs further research. The content of Eleutheroside compounds in the leaves of $A$. senticosus is less than those in the roots and pulp. It is speculated that the leaves cannot replace the roots as the medication site.

\section{CONCLUSIONS}

We analyze the roots, leaves, and pulp of $A$. senticosus through UPLC-HDMS and multivariate statistical analysis. 47 components were identified in A. senticosus and they had been assigned to different parts. The results showed a clear separation between the roots, leaves, and pulp of $A$. senticosus. The content of Eleutheroside D and E is so much higher than those in the leaves and pulp. It may be one of the reasons why the roots can be the medication site of $A$. senticosus. The content of Eleutheroside $\mathrm{B}$ is similar between the roots and the pulp. This result laid a certain foundation for the pulp of $A$. senticosus to replace the roots as the medication site in some pharmacological effects, but it still needs further research. The leaves cannot replace the roots as the medication site due to the low content of Eleutheroside compounds. The study laid the foundation for the rational utilization of $A$. senticosus resources.

\section{Acknowledgments}

This work was sponsored by the Doctoral Startup Fund of the Henan University of Animal
Husbandry and Economy (2019HNUAHEDF036), Henan Provincial Department of Science and Technology Research Project (Grant no. 202102110250), and Discipline project of Chinese veterinary medicine, Henan University of Animal Husbandry and Economy (41000003). We are very much thankful to the Henan Academy of Agricultural Sciences for providing facilities for research and analysis.

\section{Conflict of interests}

The authors declare that they have no conflict of interest.

\section{REFERENCES}

1. Han Y., Zhang A., Sun H., Zhang Y., Meng X., et al.: J. Sep. Sci. 40, 2178 (2017).

2. Sun H., Liu J., Zhang A., Zhang Y., Meng X., et al.: J. Sep. Sci. 39, 496 (2016).

3. Lau K.M., Yue G.G., Chan Y.Y., Kwok H.F., Gao S., et al.: Chin. Med. 14, 25 (2019).

4. Hu J., Shang H., Li J., Zhang L., Zhang J., et al.: J. Evid. Based Med. 3, 37 (2010).

5. Wang K., Wu J., Duan X., Zhang D., Lin X., et al.: Complement. Ther. Med. 43, 208 (2019).

6. Meng F., Li Y., He G., Ge G., Liu S.: Fitoterapia 117, 118 (2017).

7. Yan Z., Liu J., Lu D., Narlawar R., Groundwater P., et al.: Nat. Prod. Res. 28, 144 (2014).

8. Kuzniewski R., Zaluski D., Olech M., Banaszczak P., Nowak R.: Nat. Prod. Res. 32, 448 (2018).

9. Wang Y., Wang R., Shi L., Liu S., Liu Z., et al.: Food Funct. 9, 6555 (2018).

10. Shi X., Yang Y., Ren H., Sun S., Mu L., et al.: Phytochem. Lett. 35, 175 (2020).

11. Gao S., Yang R., Peng Z., Lu H., Li N., et al.: Sci. Rep. 6, 30142 (2016).

12. Shao F., Zhang L., Guo J., Liu X., Ma W., et al.: Sci. Rep. 9, 17647 (2019).

13. Ivanisevic J., Want E.J.: Metabolites 9, 308 (2019).

14. Wang Y., Caldwell R., Cowan D.A., LegidoQuigley C.: Anal. Chem. 88, 2243 (2016).

15. Cajka T., Vaclavikova M., Dzuman Z., Vaclavik L., Ovesna J., et al.: J. Sep. Sci. 37, 912 (2014).

16. Chen D.Q., Cao G., Chen H., Argyopoulos C.P., Yu H., et al.: Nat. Commun. 10, 1476 (2019).

17. Wang M., Chen L., Liu D., Chen H., Tang D.D., et al.: Chem. Biol. Interact. 273, 133 (2017).

18. Li C., Zhang J., Wu R., Liu Y., Hu X., et al.: Anal. Chim. Acta. 1063, 47 (2019). 
19. Zang X., Jones C.M., Long T.Q., Monge M.E., Zhou M., et al.: J. Proteome Res. 13, 3444 (2014).

20. Zhang A.H., Sun H., Han Y., Yan G.L., Yuan Y., et al.: Anal. Chem. 85, 7606 (2013).

21. Zhao Y.Y., Cheng X.L., Wei F., Bai X., Tan X.J. et al.: J. Proteome Res. 12, 692 (2013).
22. Zhao Y.Y., Liu J., Cheng X.L., Bai X., Lin R.C.: Clin. Chim. Acta. 413, 642 (2012).

23. Mie A., Laursen K.H., Aberg K.M., Forshed J., Lindahl A., et al.: Anal. Bioanal. Chem. 406, 2885 (2014).

24. Graczyk F., Orzechowska B., Franz D., Strzemski M., Verpoorte R., et al.: J. Ethnopharmacol. 268, 113636 (2021).

(C) 2021 by Polish Pharmaceutical Society. This is an open-access article under the CC BY NC license (http://creativecommons.org/licenses/BY/4.0/). 